\title{
Meta Modelling FOR EA BASED DESIGN OPTIMIZATION
}

\author{
BHATTACHARYA, $M$.
}

Abstract: Engineering designs often involve finding solutions to complex design optimization problems. Other examples of real world problems that involve complex optimization are large-scale finite element analysis (FEA), computational fluid dynamics (CFD), etc. Stochastic, zero-order search techniques like evolutionary algorithms (EAs) are efficient global optimizers. However, these methods require numerous evaluations of candidate solutions. For the real world problems, like engineering design optimization, large scale finite element analysis (FEA), such evaluation of one single function could involve hours to days of complete simulation. The solution to this problem lies in reducing the number of such evaluations without significantly compromising the accuracy of the results. This chapter describes how meta modelling can be used to achieve this, with an example of the DAFHEA-II (enhanced Dynamic Approximate Fitness based Hybrid Evolutionary Algorithm) technique.

Key words: Design optimization, Evolutionary Algorithm, Approximation, Meta model, Global optimizer
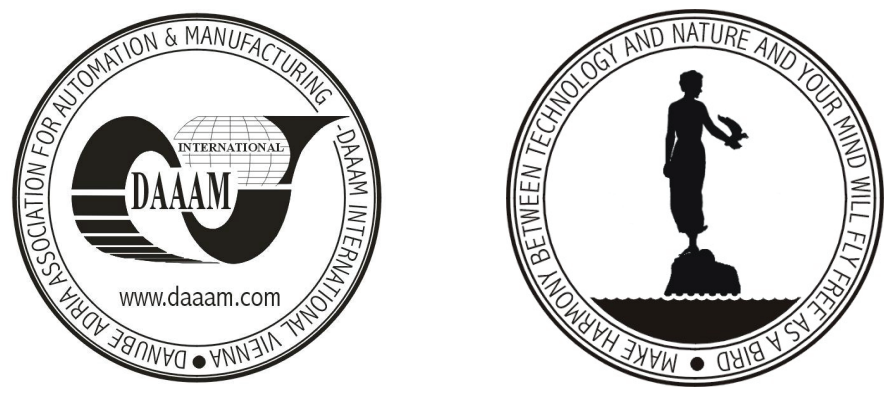

Authors' data: Bhattacharya M.[aumita], Lecturer in Information Technology, SEIS, Charles Sturt University, PO Box: 789, Albury, NSW 2640, Australia, maumita.bhattacharya@ieee.org

This Publication has to be referred as: Bhattacharya, M. (2006). Meta Modelling for EA Based Design Optimization, Chapter 03 in DAAAM International Scientific Book 2006, B. Katalinic (Ed.), Published by DAAAM International, ISBN 3-90150947-X, ISSN 1726-9687, Vienna, Austria

DOI: $10.2507 /$ daaam.scibook.2006.03 